addressed to the interests and needs of its members. A conference on 'Language for Development in Eastern Africa' was held in Nairobi from 30 May to 2 June 1970. The first issue of the Journal of the Language Association of East Africa (1970), edited by Tom Gorman and published by the East African Publishing House, Nairobi, contains a Foreword on the Language Association of Eastern Africa and articles, abstracts, book reviews, and notes and news.

\title{
Abe Bailey Institute of Inter-Racial Studies at the University of Cape Town
}

THE Abe Bailey Institute of Inter-Racial Studies was established in 1968 and is financed by the Abe Bailey Trust. It works in close co-operation with the University of Cape Town although not a formal part of it. The primary purpose of the Institute is to promote and conduct research into inter-group relations in South Africa, especially into relations between race and language groups. It will also be concerned with educational work and will co-operate with existing organizations within and outside the University in the arrangement of lectures and discussions in order to promote a better understanding of inter-group relations. The Director is Professor Hendrik W. van der Merwe and the programme is under the supervision of an academic advisory committee.

The research programme of the Institute includes a study of white South African élites, financed by the Human Sciences Research Council, and originally started under the auspices of the Institute for Social and Economic Research at Rhodes University in 1966. The report on this project is being prepared by the Director, Mrs. N. C. J. Charton and Mr. M. J. Ashley. Dr. R. E. van der Ross has received financial assistance from the Institute towards his study of the political-cultural development of the coloured people during the twentieth century as related to problems of group identity. A series of research seminars has been held and it is hoped to arrange research workshops of 4-6 people to promote discussion between Afrikaans- and English-speaking academics on inter-group relations in South Africa. The future role of the Institute is seen as not only to conduct its own research projects but also to encourage and co-ordinate research between the University of Cape Town and other universities.

\section{Université Mohammed V: Centre Universitaire de la Recherche Scientifique, Rabat (Maroc)}

THE Centre has issued a Bulletin Signalétique listing some 350 papers and other written studies, including twenty-five doctoral theses, presented during the period 1957-69. The text is in French and in Arabic. The first number of the Bulletin de la Societé d'Histoire du Maroc (in French and Arabic) has also recently appeared. Published under the auspices of the Centre Universitaire de la Recherche Scientifique, it may be ordered from the Société des Sciences de l'Homme, Avenue Moulay Cherif, B.P. I054, Rabat; price 8 dirhams (Maroc), 9 dirhams (étranger).

\section{'The Conch'}

The Conch, a bilingual (English and French) sociological journal of African cultures and literatures, was founded in 1967 in memory of the poet Christopher Okigbo. Its field of interest includes all forms of oral and written communication (traditional folklore, myths, legends, and music), factors of social change including modern mass media, poetry, and the novel in Africa. It is edited from the English Department of the University of Texas, Austin, by Dr. S. O. Anonzie. Vol. ii, no. 2 (September 1970) is devoted to 'Structuralism 